Editorial

\section{The tripod of success!}

\section{Editorial}

To paraphrase one of G. V. Black's famous quotations: The dental healthcare professional has no greater privilege than to be a student for life. The dental surgeon's lifelong continuum for education is underpinned by continued professional growth \& responsibility as part of a science that is undergoing constant change \& advancements at a very rapid rate. In today's situation, it may be a cause of concern if a dentist fails to seek out \& learn something new about dentistry every single day of his professional career. It is a great honor \& privilege for me to be writing the Editorial for the current issue of 'Journal of Dental Health, Oral Disorders \& Therapy'. It is said, 'Hit the iron when it is hot'. Allow me to take this opportunity to introduce the readers to THREE concepts that I believe, make up the 'Tripod of Success' in modern day dentistry. In today's scenario where the patient is becoming increasingly aware \& demanding, it is very important to imbibe EVIDENCE BASED DENTISTRY. Apart from formulating the right treatment plan for the patient, Evidence Based Dentistry helps safeguard the dental surgeon in cases of legal entanglements \& other ethical \& moral boardrooms. This is primarily where the role of journals \& research verticals come into play. It is important to armor the global dentist with knowledge, which is possible only when one has access to good quality literature that may help the dental surgeon keep himself/herself abreast with the global pace of the ever-changing face of dentistry.

Today's dental industry is more often than not, a finance driven industry where an old marketing phrase holds true, 'Consumer is King'. In such a stiffly competitive, dynamic \& at times volatile scenario, it is of utmost importance to make sure one does not lose the race. If the gold standard of success in dentistry is 'Quality \& Ethics', unfortunately the silver standard is 'Marketing'. Being a healthcare specialty, the best way to market oneself as a dental surgeon is to offer PAINLESS DENTISTRY. This is justified by an old quotation by Ogden Nash, "Some pains are physical and some pains are mental, but the one that is both, is dental". The fear of the dentist is still the greatest deterrent for patients to visit the dental office. With

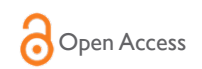

CrossMark
Volume I Issue 3 - 2014

\author{
Saurabh Lall \\ Department of Periodontology and Implant Dentistry, ESIC \\ Dental College \& Hospital, India
}

Correspondence: Saurabh Lall, Department of Periodontology and Implant Dentistry, ESIC Dental College \& Hospital, India, Email saurabhlall.delhi@gmail.com

Received: July 12, 2014 | Published: July 14, 2014

technological advancements, sophisticated equipments \& atraumatic techniques; painless dentistry is no rocket science. The catch lies in the fact that the dental surgeon needs to be aware of these research developments \& their clinical applications. If mastered, Painless Dentistry has no bounds to success.

The Hippocratic Oath renders every doctor to 'Primum non nocere', which means 'Do No Harm'. With cutting edge research breakthroughs in dentistry, it is clear that the more we invade the more surgical trauma we create. Hence, MINIMALLY INVASIVE DENTISTRY completes the tripod of success. The Gen-Y dental surgeon needs to realize the importance \& adopt the principle of Minimally Invasive Dentistry because this concept makes dental treatment much more predictable. By treading a conservative approach, we can make sure we are doing no harm to our patients who in turn reciprocate by returning the favor in the form of faith \& loyalty.

\section{Acknowledgments}

None.

\section{Conflict of interest}

The author declares that there is no conflict of interest. 